\title{
Foreword: ageism affects all of us negatively - and the law can help
}

Ageing has become an almost universal experience. A century ago, only a small minority of the population was fortunate enough to live up to old and very old age. Since then, life expectancy has increased considerably, in many countries coming close to (or exceeding) the age of 80 years. This is good news: we are able to live a full life span, from childhood and adolescence over young and middle adulthood to old age. Compared to the living situation of older people a century ago, in many countries the material living conditions of older people with respect to income and wealth as well as health and long-term care have improved, although there are still large inequalities between and within countries.

Despite the undeniable progress in life expectancy and the standard of living, we are struggling with stereotypes, prejudice and discrimination concerning older people. These stereotypes, prejudice and discrimination are the basis for ageism, the complex and usually negative social construction of old age. Ageism is based on social constructions. It is manifested in the ways we think, feel and act towards age and ageing - and these social constructions influence the way people grow old. This concerns not only "them", but all of us, as we move towards old age. Ageism restricts the realm of opportunity for older people: societal norms control the way older people are allowed to behave. Just think about indignant responses when older people violate these expectations. For instance, an old woman who spends all her money on luxury cars and travels all over the world, "wasting" her children's future inheritance, violates the expectations of old mothers. Or imagine an old man, dressing in fashionable and provocative outfits - "not appropriate for his age". Sharp reactions, from malicious remarks to open outrage, demonstrate the power of ageism.

More severely, ageism can lead to discrimination. This is the case when older people are denied access to jobs or to healthcare services, simply because of their age. And, let's not fool ourselves: ageism does not start when people turn 65; ageism often starts much earlier. In certain business sectors, turning 40 can make you "too old" for a job. Ageism reinforces social inequality as it is more pronounced towards older 
women, poor people, people with disability or those with dementia. Moreover, ageism hurts society as a whole as it hinders older people from realizing their full potential.

Ageism is not a rare phenomenon, just the opposite is true: a recent study based on the European Social Survey (The Everyday Ageism Project, www.eurage.com) found that ageism is the most prevalent type of discrimination reported by almost 35 per cent of all participants over the age of 18. Hence, ageism can (and eventually will) affect most of us as we move along the life course.

The basis of ageism is mechanisms of social categorization and stereotyping. As humans, we deal every day with huge amounts of information, and categorization is a useful mechanism to assist individuals with processing the large amounts of information we are confronted with. Categorization allows us to handle diversity and enables us to make quick decisions, especially in social contexts. There are negative effects of overgeneralization, however. If a person is classified as a member of a social group, all properties of the group are ascribed to the individual person. Hence, if a person is seen as "old", the features of the category "old" are attributed to this individual person. Properties of the social category "old" are features like "chronically ill", "functionally impaired", and "cognitively slowed down" - even if an individual older person is neither ill nor functionally and cognitively impaired. Social categorizations come with positive or negative attitudes towards members of a group solely because of their group membership. Social psychological theories suggest that in the case of a negative group identity people try actively to dissociate from this group (for example social identity theory or terror management theory). This leads to social and spatial segregation between younger and older age groups, and reinforces societal beliefs about age groups.

What can we do against ageism? At the present time, research with regard to effective anti-ageist interventions is limited. We know, however, from other fields about potentially effective interventions. These may include raising public awareness and sensitizing civil society about ageism (for example, pointing out the ways in which the media contribute to ageist beliefs and stereotypes) and correcting false beliefs (for example, educating healthcare professionals that certain processes are due to illness and not to ageing per se). Finally, enacting, enforcing and changing laws is one important avenue to change ageism in contemporary societies. The current book is about ageing, ageism, and law in Europe. Israel "Issi" Doron from the University of Haifa (Israel) and Nena Georgantzi from the AGE Platform Europe (Brussels, Belgium) have brought together experts from Europe to comprehensively address 
this topic. The book has two parts. In the first part, Theories and Concepts, topics such as equality, inclusion/exclusion and autonomy are discussed. The second part, Realities and Legal Experiences, addresses the way laws interact with ageism, either as amplifiers or as attenuators of ageism. Taken as a whole, the book informs as to how to use the law as a tool against ageism.

This book grew out of a European research network, the COST Action "Ageism - A Multi-National, Interdisciplinary Perspective" (IS1402). COST is an EU-funded programme that enables researchers to set up interdisciplinary research networks in Europe and beyond. The researchers in this network come from 35 countries and represent a highly diverse group of established and early stage researchers as well as policy makers. As leaders of this COST Action we are grateful to our colleagues Issi Doron and Nena Georgantzi that they have used the network to produce a timely book on the role of the law in the field of ageism.

Liat Ayalon and Clemens Tesch-Romer 
Israel Doron and Nena Georgantzi - 9781788972116 Downloaded from PubFactory at 04/26/2023 03:16:51AM via free access 